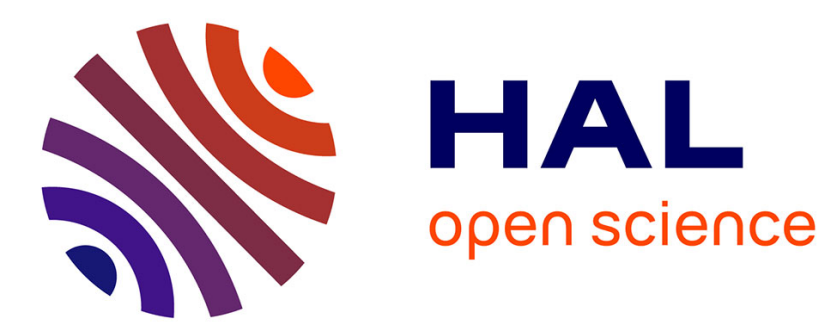

\title{
An Essential Oil Blend Prevents Pseudomonas aeruginosa PA01 from Forming Biofilms
}

Marie Lang, Sophie Rodrigues, Romain Boulho, Emmanuel Duteil, Alexis Bazire, Gilles Bedoux

\section{> To cite this version:}

Marie Lang, Sophie Rodrigues, Romain Boulho, Emmanuel Duteil, Alexis Bazire, et al.. An Essential Oil Blend Prevents Pseudomonas aeruginosa PA01 from Forming Biofilms. Journal of Bacteriology \& Parasitology, 2016, 7 (2), pp.1000268. 10.4172/2155-9597.1000268 . hal-01370450

\section{HAL Id: hal-01370450 \\ https://hal.science/hal-01370450}

Submitted on 22 Sep 2016

HAL is a multi-disciplinary open access archive for the deposit and dissemination of scientific research documents, whether they are published or not. The documents may come from teaching and research institutions in France or abroad, or from public or private research centers.
L'archive ouverte pluridisciplinaire $\mathbf{H A L}$, est destinée au dépôt et à la diffusion de documents scientifiques de niveau recherche, publiés ou non, émanant des établissements d'enseignement et de recherche français ou étrangers, des laboratoires publics ou privés. 


\section{An Essential Oil Blend Prevents Pseudomonas aeruginosa PA01 from Forming Biofilms}

Article in Journal of Bacteriology \& Parasitology • March 2016

DOI: $10.4172 / 2155-9597.1000268$

READS

48

6 authors, including:

Marie Lang

Université de Bretagne Sud

2 PUBLICATIONS 0 CITATIONS

SEE PROFILE
Romain Boulho

Université de Bretagne Sud

2 PUBLICATIONS 0 CITATIONS

SEE PROFILE 


\title{
An Essential Oil Blend Prevents Pseudomonas aeruginosa PA01 from Forming Biofilms
}

\author{
Lang Marie ${ }^{1}$, Rodrigues Sophie ${ }^{1}$, Boulho Romain ${ }^{1}$, Duteil Emmanuel ${ }^{2}$, Bazire Alexis ${ }^{1}$ and Bedoux Gilles ${ }^{1^{*}}$ \\ ${ }^{1}$ Université de Bretagne-Sud, EA 3884, LBCM, IUEM, F-56100 Lorient, France \\ ${ }^{2}$ BioArmor Development SARL, Z.I de la Gare, F- 22940 Plaintel, France
}

"Corresponding author: Bedoux Gilles, Université de Bretagne-Sud - Laboratoire de Biotechnologie et Chimie Marines Centre de Recherche Yves Coppens-Campus de Tohannic - BP 57356017 Vannes Cedex, France, Tel: (+33) 02970171 57; E-mail: gilles.bedoux@univ-ubs.fr

Received date: February 29, 2016; Accepted date: March 25, 2016; Published date: March 29, 2016

Copyright: @ 2016 Lang M, et al. This is an open-access article distributed under the terms of the Creative Commons Attribution License, which permits unrestricted use, distribution, and reproduction in any medium, provided the original author and source are credited.

\begin{abstract}
Essential oils are natural ingredients exhibiting antimicrobial and antioxidant effects. The properties of a mix of Allium sativum, Cinnamomum cassia and Mentha piperita essential oils are established in this study on a biofilm forming pathogen, Pseudomonas aeruginosa PA01.

Minimal inhibitory and bactericidal concentrations were first determined on planktonic cells for the pure essential oils, then for the blend. A crystal violet assay provided the active concentration of a blend for bacterial biofilm. Pseudomonas aeruginosa PA01 planktonic and sessile cells were affected by a concentration of an essential oil blend of $0.125 \%$. The active concentration of $0.1 \%$ was confirmed using a protocol developed on glass slides, for its activity on adhesion and biofilm formation. The experiment was then repeated in flow cells to monitor the structural biofilm development using confocal laser scanning microscopy. Pseudomonas aeruginosa PA01 adhesion was severely inhibited by the blend concentration at $0.5 \%$. Its biofilm was strongly affected from a $0.1 \%$ blend concentration and was totally eradicated when the concentration reached $1 \%$.
\end{abstract}

The essential oil blend has an enlarged spectrum of activity and is effective on early biofilm development stages, with a concentration that does not involve bactericidal activities. These results are predictive for potential use of this blend as a cleanser.

Keywords: Essential oils; Adhesion; Biofilm; Pseudomonas aeruginosa; Structural analyses; Confocal laser scanning microscopy

\section{Introduction}

Biofilms are complex structures involving different species of microorganisms, embedded in an exopolysaccharidic matrix [1]. Bacteria are able to communicate due to a quorum sensing systemnutrient, DNA and proteins being exchanged between the different protagonists [2]. Due to this structure, biofilms are resistant to disinfectants or detergents and lead to complications in many fields, such as the food industry or medical surgery [1,3]. Well known Pseudomonas aeruginosa is a pathogen able to contaminate medical devices like dentures, catheters or prosthesis, but also corporal tissue, leading to severe infections and exhibit multi-drug resistance $[4,5]$.

Although surface cleaning is strongly controlled by chemical or physical methods (mechanical scrubbing, brushing, scraping or high pressure spraying for example), it is rarely effective for total eradication of biofilms [2]. In fact, biofilms are able to adapt themselves to chemical products, leading to high resistance and new solutions have to be investigated. Enzymes, phages, interspecies competition or natural plant extracts - like volatile compounds - have been studied and offer alternatives to obtain new anti-biofilm products [6-9].

Terrestrial plants are sessile organisms, a status which forces them to adapt to biotic or abiotic stresses through the production of secondary metabolites. Biofilm development on their surface is one of the biotic stresses they have to deal with, leading to the excretion of essential oils
[10]. Essential oils are lipophilic and complex chemical mixes with high terpenic and phenolic contents. Antibacterial activities of essential oils and their components have been widely studied over the past few years [11-13]. Due to their lipophilic character, they are able to pass through cell membranes, disrupt the different phospholipids, polysaccharides and fatty acid layers, and finally permeabilize cells causing a loss of integrity. Clove, thyme or oregano essential oils among others are also able to affect bacterial biofilms specifically by interfering with quorum sensing, inhibiting the peptidoglycan synthesis or reducing cell adherence [14].

Allium sativum essential oil has proved its effectiveness against $P$. aeruginosa planktonic cells, due to the presence of diallyl sulphides, compounds containing sulphuric bounds. In their studies, Sandasi and Valeriano also showed the effectiveness of Mentha piperita essential oils against biofilms [2,3]. Kim et al. reported the particular ability of cinnamaldehyde, the main compound of Cinnamomum cassia essential oil to down regulate quorum sensing in $P$. aeruginosa biofilms [15]. As the effectiveness of these three essential oils has been reported in different publications, we associated them in order to develop products that are active during early and late biofilm formation stages. As bacteria within a biofilm are 10 to 1000 times more resistant than planktonic ones [16], we also combined essential oils in order to enlarge the antimicrobial activity spectrum. Furthermore, a biofilms' morphology is often adaptable against external growth conditions, linked to differences in susceptibility. To prove specific anti-biofilm activity, we tested the blend against both planktonic and sessile bacteria. 


\section{Materials and Methods}

\section{Plant extracts}

The essential oils (EOs) used in this study were purchased from BioArmor Développement SARL (Plaintel, France). Gas chromatography coupled with mass spectrometry (GC-MS) reports detail the major constituents, and were joined with each EO. Cinnamomum cassia essential oil (CEO) was distilled from leaves and branches, Allium sativum essential oil (AEO) was extracted from pods and Mentha piperita essential oil (MEO) was extracted from leaves. All EOs were extracted by a steam distillation process and were stored in the dark at $4^{\circ} \mathrm{C}$

\section{Bacteria and culture conditions}

Pseudomonas aeruginosa PAO1 was grown aerobically in Lysogeny broth (LB) medium ( $\mathrm{g} \mathrm{l}^{-1}: \mathrm{NaCl}$ 10; Tryptone, 10; Yeast Extract, 5) at $37^{\circ} \mathrm{C}$ overnight. $\mathrm{NaCl}$ was purchased from Fischer, France; Triptone and Yeast Extract were purchased from Dutscher, France. The bacterial strain was stored at $-80^{\circ} \mathrm{C}$ in $20 \%$ (v/v) glycerol.

\section{Minimal inhibitory concentrations (MIC) and minimal bactericidal concentrations (MBC) of the EOs and blend}

The antibacterial activity of the EOs and the blend was measured using a broth dilution method in microplates, adapted from a previously described protocol [17]. CEO, AEO and MEO and the blend were diluted in LB medium within a range of $0.5 \%$ to $0.005 \%$ $(\mathrm{v} / \mathrm{v})$. The same amount of an Ethoxylated Castor Oil (ECO) based emulsifier was added, as for the EO. A volume of $195 \mu \mathrm{l}$ of each dilution was placed in the wells of a flat bottomed 96 well microplate and bacterial suspension were added to obtain a final Optical Density (OD) of 0.0125 at $600 \mathrm{~nm}$ (Shimadzu UV-1800 spectrophotometer Shimadzu Europa GmBh, Duisburg, Germany). Microplates were incubated for $24 \mathrm{~h}$ at $37^{\circ} \mathrm{C}$ without agitation. After cell growth, a tetrazolium salt (MTT, Sigma Aldrich, France) solution in DMSO (Fisher, France) was added to each well at a final concentration of 90 $\mu \mathrm{g} \mathrm{ml}{ }^{-1}$ for $30 \mathrm{~min}$. This allowed viable microorganisms to metabolize the yellow MTT into purple formazan crystals. An aliquot of each well which did not present a formazan production was then spread on LB agar plates, incubated for $24 \mathrm{~h}$ at $37^{\circ} \mathrm{C}$ for the determination of minimal inhibitory concentrations (MIC) or minimal bactericidal concentrations (MBC). MIC and MBC corresponded to the lower concentrations leading to growth or absence of growth, respectively, after spreading. Each test was carried out independently in triplicate.

\section{Anti-biofilm crystal violet assay}

Crystal violet assay is a rapid method for the observation of biofilm inhibition $[2,10]$. EOs was diluted in a LB medium as before. Solution of Gentamycin (Sigma Aldrich, France) at $50 \mu \mathrm{g} \mathrm{ml}^{-1}$ was used as a positive control. LB medium was used as a negative control. Wells without bacteria inoculation were also used to control the final washing step. For the attachment step, overnight cultures of bacteria were centrifuged for $5 \mathrm{~min}$ at $2500 \mathrm{~g}$ and the cells were then suspended in sterile physiological saline (SPS $0.9 \% \mathrm{NaCl}$ ) and adjusted at an OD of 0.1 at $600 \mathrm{~nm}$. A volume of $200 \mu \mathrm{l}$ of this suspension was first placed in a 96 well microplate for adhesion. After $2 \mathrm{~h}$, the wells were rinsed twice with SPS and filled with the different tested conditions. After 24 $\mathrm{h}$ incubation at $37^{\circ} \mathrm{C}$ without agitation, the medium was removed and the wells were rinsed twice with SPS in order to eliminate planktonic cells. In each well, $200 \mu \mathrm{l}$ of a $1 \%$ crystal violet staining solution in water (Reactif RAL purchased by Servilab, Le Mans, France) was added and rinsed with SPS after 15 minutes until the well which was not inoculated with bacteria was totally colourless. Crystal violet contained in the bacteria was then solubilized with $70 \%$ ethanol (Fischer, France) and the OD was read at $600 \mathrm{~nm}$ with a Multiskan ${ }^{\mathrm{TM}}$ GO Microplate Spectrophotometer (ThermoFisher, Illkirch, France). Each test was conducted in triplicate.

\section{Confirmation of active concentration on glass slides}

\section{Cell adhesion and biofilm culture}

For an adhesion step, clean and sterile glass slides were immersed in SPS (control), in SPS with $0.1 \%$ ECO or in SPS with $0.1 \%$ ECO and $0.1 \%$ EO blend. For each condition, a working solution was inoculated at $0.1 \mathrm{OD}$ at $600 \mathrm{~nm}$ with overnight culture of bacteria. After $2 \mathrm{~h}$, glass slides were carefully rinsed once in SPS to remove non-attached bacteria.

For biofilm formation, bacterial adhesion was performed in SPS as previously described. After $2 \mathrm{~h}$, the glass slides were carefully washed once with SPS, and immersed in LB, LB with $0.1 \%$ ECO or LB with $0.1 \% \mathrm{ECO}$ and $0.1 \% \mathrm{EOB}$. After $24 \mathrm{~h}$ of growth at $37^{\circ} \mathrm{C}$ without agitation, the slides were rinsed once with SPS before staining. Each experiment was conducted in triplicate.

\section{Fluorescence microscopy}

Attached cells and biofilm were observed with an Olympus BX43 fluorescence microscope (Olympus microsystems, Hamburg, Germany) powered by the X-cite $120 \mathrm{q}$ led fluorescence illuminator (Lumen dynamics) using a 100x oil immersion lens. Bacteria were detected by immersion in a $28.55 \mu \mathrm{M}$ DAPI solution, for $10 \mathrm{~min}$ in the dark. After staining, the slides were washed once in SPS to remove the excess of dye and covered with cover glasses to enable observation. Three images were taken per slide. The glass surfaces covered by attached bacteria were evaluated by using the Image software (National Institutes of Health, USA).

\section{Anti-biofilm activity tested in flow cells}

\section{Cell adhesion and biofilm culture}

Biofilm was grown at $37^{\circ} \mathrm{C}$ under dynamic conditions in a three channel flow cell $(1 \times 4 \times 44 \mathrm{~mm}$; Biocentrum DTU, Denmark $)$ [18]. The flow system was assembled, prepared and sterilized as described before [19]. The substratum consisted of a microscope glass coverslip $(24 \times 50$ st 1 ; KnittelGlasser, Braunschweig, Germany).

For the adhesion step each channel was inoculated with $250 \mu$ of an overnight bacterial culture diluted to an OD of 0.1 at $600 \mathrm{~nm}$ in SPS, or in SPS containing $0.5 \%$ or $1 \%$ ECO, or in SPS containing $0.5 \%$ or $1 \%$ EOB (with the same amount of ECO). ECO (10\% mother solution in SPS) was filtered on a $20 \mu \mathrm{m}$ sterile membrane to enhance the quality of the images. Bacteria were allowed to attach to the glass substratum during $2 \mathrm{~h}$ at room temperature without flow. A constant flow $(2.5 \mathrm{ml}$ $\mathrm{h}^{-1}$ ) of SPS using a Watson Marlow 205U peristaltic pump (Watson Marlow, Falmouth, United Kingdom) was then applied for 15 min in order to remove non-attached cells. Attached bacteria were observed by confocal laser scanning microscopy (CLSM) as described below. This experiment was conducted in duplicate and three images were taken per channel. 
Page 3 of 8

For biofilm formation, each channel of the flow cell chamber was connected to LB medium, or LB medium supplemented with ECO $(0.1 \%$ or $1 \%)$ or else with the EOB $(0.1 \%$ or $1 \%)$. The channels were inoculated with $250 \mu \mathrm{l}$ of a bacterial suspension diluted in SPS to an OD of 0.1 at $600 \mathrm{~nm}$. A two-hour attachment step was performed as described before, and a flow $\left(2.5 \mathrm{ml} \mathrm{h}^{-1}\right)$ of the medium was then applied for $24 \mathrm{~h}$. Biofilms were observed by CLSM as described below. Each experiment was conducted in triplicate and three images were taken per channel.

\section{Confocal Laser Scanning Microscopy (CLSM)}

Attached bacteria and biofilm observations were performed with a TCS-SP2 microscope (Leica Microsystems, Heidelberg, Germany), using a $63 \mathrm{x}$ oil immersion lens. Bacteria were detected after cell attachment by staining with $5 \mu \mathrm{M}$ of SYTO9 green or after biofilm growth by double-labelling with $5 \mu \mathrm{M}$ SYTO9 green and $0.3 \mu \mathrm{M}$ propidium iodide (PI) (Live/Dead BacLight Bacterial Viability Kit, Invitrogen, Carlsbad, USA). The staining was performed by injecting $250 \mu \mathrm{l}$ of fluorescent dye prepared in SPS into a flow cell channel, incubating at room temperature for $15 \mathrm{~min}$ in the dark and washing for $15 \mathrm{~min}$ with a flow $\left(2.5 \mathrm{ml} \mathrm{h}^{-1}\right)$ of medium, immediately before CLSM observation. SYTO9 green was excited at $488 \mathrm{~nm}$ and fluorescence emission was detected between 500 and $550 \mathrm{~nm}$. PI was excited at $543 \mathrm{~nm}$ and fluorescence emission was detected at $620 \mathrm{~nm}$. The fluorescence signal of double-labelled specimens was acquired simultaneously.

The glass surfaces covered by attached bacteria were evaluated by using the ImageJ software. For three-dimensional (3D) visualization, images were taken every micrometer throughout the whole biofilm depth. For the processing of 3D image data (volume rendering with shadow projection), the Leica LAS AF software (Leica Microsystems, Heidelberg, Germany) was used. Quantitative analyses of image stacks were performed using the COMSTAT software (http:// www.imageanalysis.dk/) [20]. At least three image stacks from each independent experiment were used for each analysis.

\section{Statistical analysis}

Results are expressed as means \pm standard deviation (SD). The statistical analysis was carried out with Microsoft Excel 2013 using one-way analysis of variance (ANOVA) followed by a two-tailed T-test at the $5 \%$ level to evaluate differences between the samples. A $p$ value of $<0.05$ was considered significant.

\section{Results and Discussion}

\section{Essential oil analysis}

The EOs selected here were each constituted of a different family of molecules. As $\mathrm{MEO}$ was rich in terpenes, AEO was principally composed of sulphonates and the major compounds of CEO derivate from cinnamic acid. The whole composition of the EOs, determined by GC-MS, is presented in Table 1. If their global composition was in accordance with literature, the fine composition was slightly different from published data. MEO is quasi exclusively composed of terpenes $(>90 \%)$. Main compounds were menthol (32.5\%) and its derivate (DL)menthone $(26.5 \%)$, menthylacetate $(4.9 \%)$, isomenthone (4.1\%), (D)neomenthol (3.2\%), menthofuran (2.4\%) and pulegone (1.6\%). Other terpenes like eucalyptol (4.7\%), D-limonen (3.2\%) and alpha/betapinen $(2.6 \%)$ and the sesquiterpene $\beta$-caryophyllen (3.7\%) also make up its composition. The qualitative and quantitative compositions are similar to those presented in further published data [21]. The plants from genius Allium are well known to be rich in sulphinates (69.8\%) and the main components of AEO were identified as diallyl disulphides (53.5\%) diallyl trisulphides (9.4\%) and diallyl sulphides (6.9\%).

\begin{tabular}{|c|c|c|c|c|c|c|}
\hline Plant & \multicolumn{2}{|l|}{ Cinnamomum cassia (CEO) } & \multicolumn{2}{|c|}{ Mentha piperita (MEO) } & \multicolumn{2}{|c|}{ Allium sativum (AEO) } \\
\hline Organ & \multicolumn{2}{|l|}{ Leaves, Branches } & \multicolumn{2}{|l|}{ Leaves } & \multicolumn{2}{|l|}{ Pods } \\
\hline \multirow[t]{11}{*}{$\begin{array}{l}\text { Essential oil } \\
\text { Composition }\end{array}$} & Cinnamaldehyde & $79.9 \%$ & Menthol & $32.5 \%$ & $\begin{array}{l}\text { Diallyl } \\
\text { disulphides }\end{array}$ & $53.5 \%$ \\
\hline & o-Methoxy cinnamaldehyde & $8 \%$ & (DL)-Menthone & $26.5 \%$ & $\begin{array}{l}\text { Diallyl } \\
\text { trisulphides }\end{array}$ & $9.4 \%$ \\
\hline & Cinnamyl acetate & $2.5 \%$ & Menthyl acetate & $4.9 \%$ & $\begin{array}{l}\text { Diallyl } \\
\text { sulphides }\end{array}$ & $6.9 \%$ \\
\hline & Coumarin & $1.5 \%$ & Eucalyptol & $4.7 \%$ & Propene & $6.7 \%$ \\
\hline & Benzaldehyde & $0.8 \%$ & Isomenthone & $4.1 \%$ & & \\
\hline & Styrene & $0.2 \%$ & $\beta$-caryophyllen & $3.7 \%$ & & \\
\hline & Cinnamic alcohol & $0.1 \%$ & D-neomenthol & $3.2 \%$ & & \\
\hline & Cinnamic acid & $0.1 \%$ & D-limonen & $3.2 \%$ & & \\
\hline & D-limonen & $0.04 \%$ & $\alpha / \beta$-pinen & $2.6 \%$ & & \\
\hline & & & Menthofuran & $2.4 \%$ & & \\
\hline & & & Pulegone & $1.6 \%$ & & \\
\hline
\end{tabular}

Table 1: Main components (\%) detected by GC-MS in the three EOs tested. 
A low presence of propene (6.7\%) was also detected. Reported concentrations of disulphides are quite low (from $29.1 \%$ to $36.5 \%$ ), and the rate of trisulphides is higher in other published data (from $21.6 \%$ to $30 \%)[22,23]$. In CEO, a majority of components derive from cinnamic acid (0.1\%) like cinnamaldehyde (79.9\%) which was identified as a major compound, o-methoxycinnamaldehyde (8\%), cinnamyl acetate (2.5\%), coumarin (1.5\%), benzaldehyde $(0.8 \%)$ and also styrene $(0.2 \%)$ and cinnamic alcohol (0.1\%). A low concentration of terpenes is present in the form of d-limonen $(0.04 \%)$. This composition is in accordance with most of the published data [24] but diverge from data published by Murbach Teles Andrades et al. [25], where the main compound was eugenol $(72.1 \%)$. This change in main compound can be explained by the use of leaves instead of branches.

An EO's activity is generally related to the main compounds present (menthol, diallyl sulphides and cinnamaldehyde here), even if the activity of the totum should be taken into account. The cinnamaldehyde and eugenol molecular family are extremely different, the presence of a phenolic cycle leads to various activities: as cinnamaldehyde has been reported not to cause the disintegration of the outer membrane, eugenol leads to high degree of cell lysis [26]. Compounds present in minor concentrations may contribute to bioactivity, but are not estimated as active neither tested. Variations in EO compositions obtained from two of the same plants can generally be explained by the effect of differences in where they are sourced (climatically changes, presence of biotic or abiotic stresses), changes in treated plant parts or the extraction protocol. Several parameters can influence the EO compositions, which leads to modifications in their biological properties [27]. As the main compounds presented here belong to different molecular families, we assume that their blend could target diverse cellular mechanisms.

\section{Antibacterial activity of EOs and blend}

MIC and MBC against PAO1 were evaluated for each EO and the blend (Table 2). EOs was diluted from 0.5 to $0.005 \%$ (v/v), a concentration range considered as the most usable regarding the literature. MEO was not active in the tested concentrations but Tsai et al. [28] obtained a MIC of $0.92 \%$ on PAO1. The activity of monoterpenes and especially menthol has been studied by Trombetta et al. on models. They proved that this molecule and other terpenes were able to enhance membrane fluidity, leading to expansion, altered respiration and destabilisation of intramembranous proteins [29]. AEO inhibited the growth of PAO1 at a concentration of $0.5 \%$. As described by Casella et al. [23], the activity of AEO is due to the presence of diallyl sulphides and diallyl disulphides. These molecules derive from allicin, naturally present in garlic, which acts on planktonic bacteria and on biofilms [30,31]. The presence of sulphuric bounds is a key for sulfhydryl dependent enzyme inactivation [32]. Through their work, Chen et al. [33] also highlighted an $\mathrm{N}$-acetyl transferase inhibition activity induced by diallyl sulphides and diallyl disulphides on Klebsiellia pneumoniae. As PAO1 also possesses this enzyme, it can be assumed that both molecules act due to the same mechanism [34]. CEO was the most active of the three tested EOs and was bactericidal at a concentration of $0.125 \%$. The activity of CEO and mostly cinnamaldehyde has already been reported for $P$. aeruginosa and other bacteria like Escherichia coli and Listeria monocytogenes [35,36]. Among these previous results, cinnamaldehyde was found to inhibit the Z-ring formation during cell division, by targeting FtsZ protein. Contrary to terpenic compounds, cinnamaldehyde has not been reported to disintegrate the membrane or interfere with ATP formation [37].
The minor differences in active concentrations compared to published data could be explained by slight composition changes as described above (section 3.1) and the use of ECO in our test leading to physico-chemical changes. Glover et al. [38] observed an enhancement of bacterial membrane fluidity when surfactants were added to the growth medium, which was not correlated with high mortality in the case of alcohol ethoxylates.

The three EOs were mixed at an equal concentration (EOB) to evaluate a potential synergistic effect. An inhibiting activity on PAO1 was observed at $0.125 \%$ concentration and it became bactericidal at $0.25 \%$. As the EOs were three-times less concentrated in the blend, the appearance of an inhibiting activity at $0.125 \%$ and the conservation of a bactericidal effect suggests a synergistic activity between the EOs. An eventual synergistic activity between Cinnamon, Garlic and Peppermint EOs has not been reported yet. It is unusual to study a blends' activity on planktonic and sessile bacteria and the results highlight the benefit of forming an EOs blend.

\begin{tabular}{|l|l|l|}
\hline & CMI \% (v/v) & CMB \% (v/v) \\
\hline AEO & 0.500 & $>0.500$ \\
\hline CEO & - & 0.125 \\
\hline MEO & $>0.500$ & $>0.500$ \\
\hline EOB & 0.125 & 0.250 \\
\hline
\end{tabular}

Table 2: CMI and CMB of AEO (Allium sativum Essential Oil), CEO (Cinnamomum cassia Essential Oil), MEO (Mentha piperita Essential Oil) and their blend (EOB) on PAO1.

\section{Anti-biofilm concentration of EOB}

The crystal violet assay was performed, in order to screen the activity of the blend (EOB). As a first result, we observed that the ECO emulsifier at a maximal concentration of $0.5 \%$ had no effect on biofilm formation (data not shown). Using the minimal blend concentration of $0.005 \%$, a slight enhancement of PAO1 biofilm formation was observed, corresponding to a non-significant increase (Figure 1a). Increasing the concentration at $0.25 \%$ led to a total biofilm inhibition $(101 \pm 4 \%)$. Inhibition approximately became stable when the blend's concentration reached $0.1 \%$, an amount of EOB that we conserved for the next steps of our study. In their publication, Kim et al. also showed a $49 \%$ reduction of $P$. aeruginosa biofilm formation at $0.1 \%$ concentration of CEO according to a 96 well microplate assay [15], suggesting a synergistic effect of EOB.

\section{Confirmation of active concentration on glass slides}

Biofilm formation is a process described in different stages, including reversible cell adhesion, non-reversible adhesion, formation of micro-colonies and macro-colonies, leading to the detachment of planktonic cells [4].

Results obtained for cell adhesion on glass slides are presented in Figure $1 \mathrm{~b}$. Under control conditions, PAO1 adhered to the glass slides and covered respectively $12.9 \pm 6.7 \%$ of the surface. When ECO was added to SPS, attached bacteria seemed to be fewer and less uniform among the slide, but the covered area decreased non-significantly to $10.4 \pm 6.5 \%$. This result confirmed the absence of the activity of ECO. After a $2 \mathrm{~h}$ treatment with the EOB, the adhesion rate decreased significantly $(\mathrm{P}<0.001)$, reaching only $1 \pm 1.1 \%$. As $\mathrm{EOB}$ was active at a 
Citation: Lang M, Rodrigues S, Boulho R, Duteil E, Bazire A, et al. (2016) An Essential Oil Blend Prevents Pseudomonas aeruginosa PA01 from Forming Biofilms. J Bacteriol Parasitol 7: 268. doi:10.4172/2155-9597.1000268

Page 5 of 8

sublethal concentration, we can consider that it has an anti-adhesive activity, maybe by disrupting the complex cellular processes leading to the development of the adhesive structure [39]. The activity of the other essential oils or components like carvacrol or thymol on early biofilm formation steps has been reported before, and can be related to an inhibition of flagella formation observed on E. coli $[39,40]$.

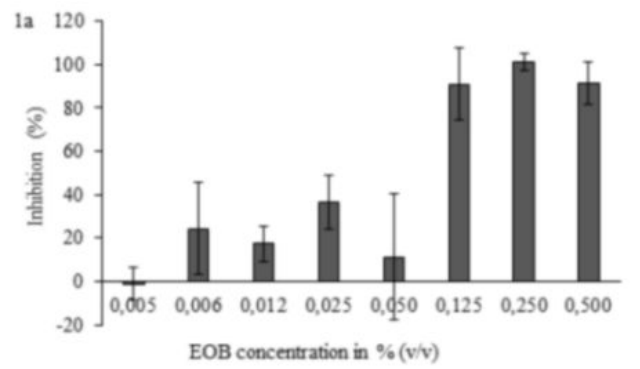

Figure 1a: Impact of a $24 \mathrm{~h}$ EOB treatment, with different concentrations ranging from $0.005 \%$ to $0.5 \%$, on PAO1 biofilm formation. Biofilms were grown in the wells of a microplate, using the LB medium and increasing concentrations of EOB. In each well ECO was used as emulsifier in same concentrations related to EOB. Use of ECO at a maximal concentration of $0.5 \%$ did not cause any inhibition. Biofilm was quantified after a $24 \mathrm{~h}$ incubation using crystal violet. Experiments were carried out in triplicate $(n=3)$ and error bars indicate the standard deviation from the mean.

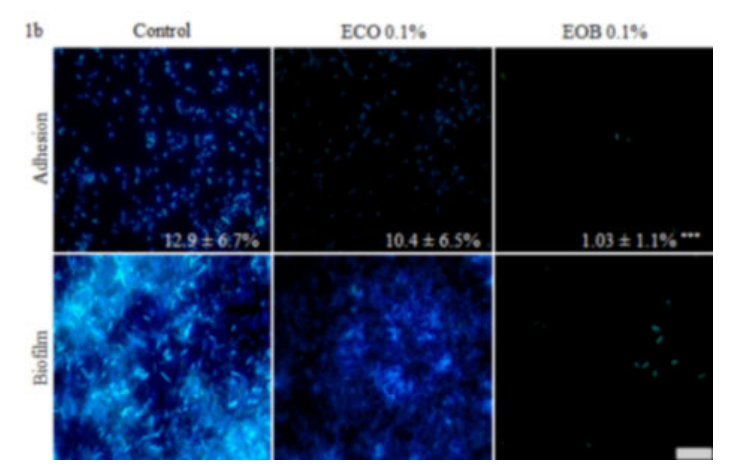

Figure 1b: Fluorescence microscopic visualisation of PAO1 cell adhesion and biofilm formation on glass slides in different conditions. Adhesion and biofilm growth were performed in control condition, in presence of $0.1 \% \mathrm{ECO}$ or in presence of $0.1 \%$ EOB emulsified with $0.1 \%$ ECO, according to the respective protocols. Attached cells and biofilms were stained with DAPI (28.5 $\mu \mathrm{M})$ and observed at magnification $\times 1000$. Scale represents $8 \mu \mathrm{m}$. Covered area fractions of adhered cells were obtained after treatment with IMAGEJ software. Experiments were carried out in triplicate and three images were taken pro slides. Error bars represent standard deviation from the mean $(\mathrm{n}=9)$ and ${ }^{* * *} \mathrm{P}<0.001$.

When biofilm was grown under control conditions, bacteria were able to colonize the total glass surface, leading to macrocolony formations (Figure 1b, Biofilm control). When ECO was added at $0.1 \%$ to the growth medium, biofilm formation was altered (Figure $1 \mathrm{~b}$, Biofilm ECO 0.1\%). In appearance, the bacteria which adhered to the glass surface did not form identical biofilm as those observed for the control conditions (Figure 1b). After $24 \mathrm{~h}$ of EOB treatment, only few attached bacteria were still present (Figure 1b, Biofilm EOB 0.1\%).
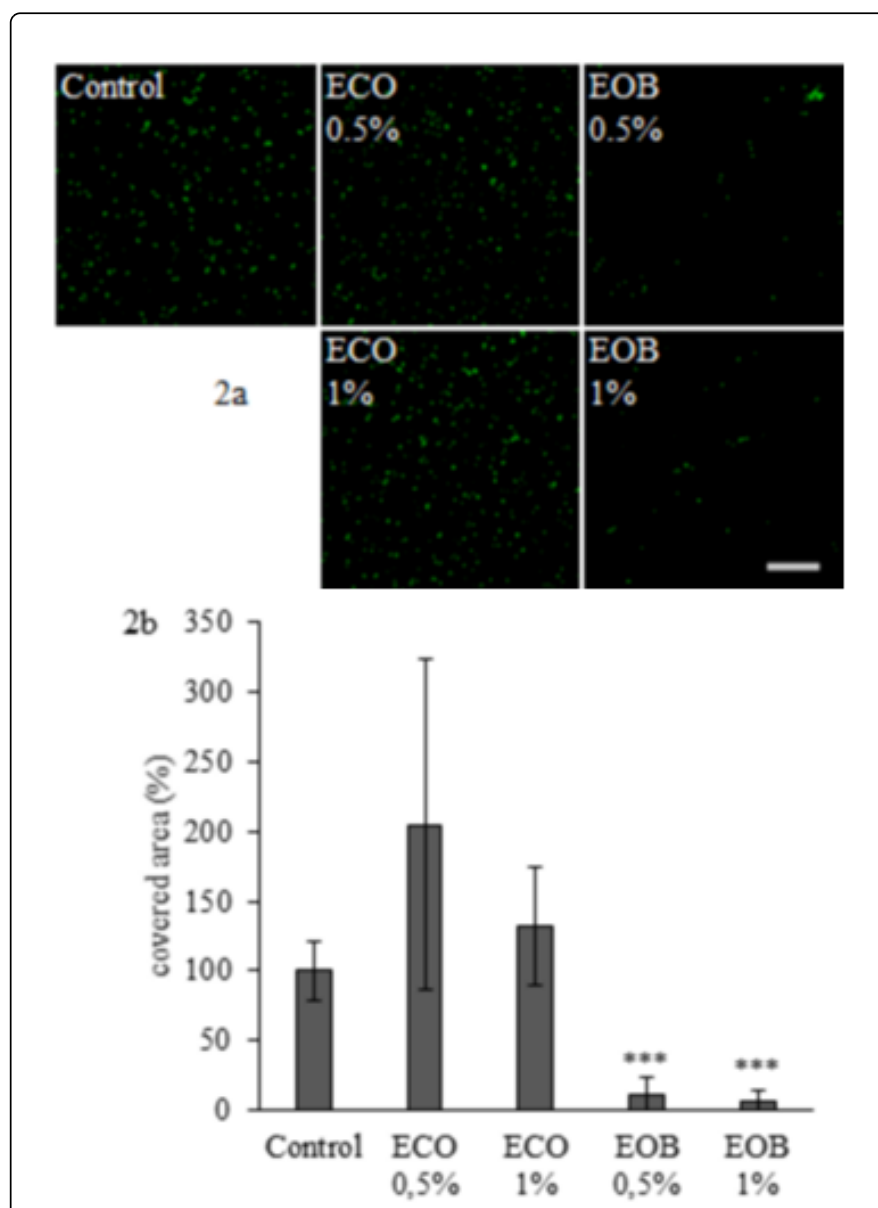

Figure 2: Fluorescence microscopic visualisation of PAO1 attached cells in different conditions (2a) and corresponding relative recovery percentage $(2 \mathrm{~b})$. Cell adhesion was carried out in control condition, in presence of $0.5 \%$ to $1 \% \mathrm{ECO}$ or in presence of $0.5 \%$ to $1 \%$ EOB emulsified with $0.5 \%$ to $1 \%$ ECO. Attached cells were observed with CLSM after SYTO9 staining at magnification x630 and scale represents $67.3 \mu \mathrm{m}$. Fractions of the covered area obtained with the IMAGEJ software are presented in figure $2 \mathrm{~b}$. Error bars represent standard deviation from the mean $(n=6)$ and ${ }^{* *} \mathrm{P}<0.001$.

\section{Bacterial adhesion and biofilm formation in dynamic conditions}

Biofilm formation was followed in a flow cell chamber (Figure 2). As previously for the adhesion step, bacteria were allowed to adhere to glass slides for $2 \mathrm{~h}$ without flow (Figures $2 \mathrm{a}$ and $2 \mathrm{~b}$ ). In the control condition, PAO1 covered a mean area of $1.3 \pm 1.1 \%$ that we considered as the $100 \%$ adhesion rate. The recovery value order of magnitude was slightly lower in these tests than those observed on glass slides (Section 3.4). As we observed no effect on bacterial adhesion with a $0.1 \% \mathrm{EOB}$ treatment, we tested both $0.5 \%$ and $1 \%$ concentrations of EOB. When ECO was added at a concentration of $0.5 \%$, the covered area was non- 
significantly doubled and increased by a factor of 1.3 when the emulsifier was added at $1 \%$. Statistical testes indicate that bacterial attachment was not significantly changed by the addition of ECO $(\mathrm{P}>0.05)$ (Figure 2b).

Treatment with $0.5 \%$ and $1 \%$ of $\mathrm{EOB}$ significantly reduced the attachment of PAO1 to the glass surface with only $10 \pm 12 \%$ and $6 \pm$ $7 \%$ of the surface remaining covered when compared to the control (Figures $2 \mathrm{a}$ and $2 \mathrm{~b}$ ). The EOB remained active at low concentrations while an enhancement of the adhesion phenomenon was observed when ECO was added to SPS. It is recognised that microorganisms are able to secrete bio-surfactants in order to enhance their motility on surfaces [41], a fact that could explain the better cell repartition when $0.5 \%$ ECO was used. As cell adhesion is a complex mechanism including the presence of motility and attachment appendix like pili, the surface tension modification can lead to the inhibition of adhesion, observed when a higher dose of ECO was added.

Biofilm growth and mortality were followed as biovolume estimation with COMSTAT software of SYTO9 and PI labelled cells respectively (Figures $3 \mathrm{a}$ and $3 \mathrm{~b}$ ). In control conditions, we observed a thin biofilm (maximal thickness $(\mathrm{Tm})$ of $11.4 \pm 1.2 \mu \mathrm{m}$ ) associated with the filamentous organization of cells (Figure 3a, Control), damaged cells were evenly distributed in all biofilm layers. In this condition, the biofilm had a total biovolume of $1.6 \pm 1.1 \mu \mathrm{m}^{3} \mu \mathrm{m}^{-2}$ with a mortality rate of $1.5 \pm 2.6 \%$ (Figure $3 \mathrm{a}$ and $3 \mathrm{~b}$ ). When $0.1 \%$ ECO was added to the medium, no significant change was observed in the total biovolume, and the mortality rate was not significantly reduced to 0.2 $\pm 0.2 \%$ (Figure 3a). The biofilm structure was however more heterogeneous since the thickness was increased (maximal thickness of $19.5 \pm 6.9 \mu \mathrm{m})$ and we did not observe any filamentous consortium (Figure 3a, ECO 0.1\%). Overall, this result is in total opposition with the observation carried out on glass slides. When the EOB was added in a $0.1 \%$ concentration to $\mathrm{LB}$, the total biovolume significantly increased to $2.6 \pm 0.94 \mu \mathrm{m}^{3} \mu \mathrm{m}^{-2}$ and mortality reached $1.5 \pm 2.7 \%$ (Figure 3 EOB $0.1 \%$ ). Thickness was close to that observed with $0.1 \%$ ECO $(18.8 \pm 2.8 \mu \mathrm{m})$ but all cells grew and formed filamentous consortia (Figure 3a, EOB 0.1\%). Filaments are a known response to sublethal stresses in some bacteria, involving the stoppage of cell division mechanism, like the FtsZ ring formation [42]. As described by Domadia et al. [37] cinnamaldehyde bind FtsZ proteins and inhibit their polymerization, which could lead to filament formation. Furthermore, the fact that filamentous cells were all stained by PI proved the limit of Live/Dead staining: in fact filamentous cells multiply in a rapid manner, which leads to a fault in the membrane integrity and a higher permeability of the PI, as the cells are still alive [42].
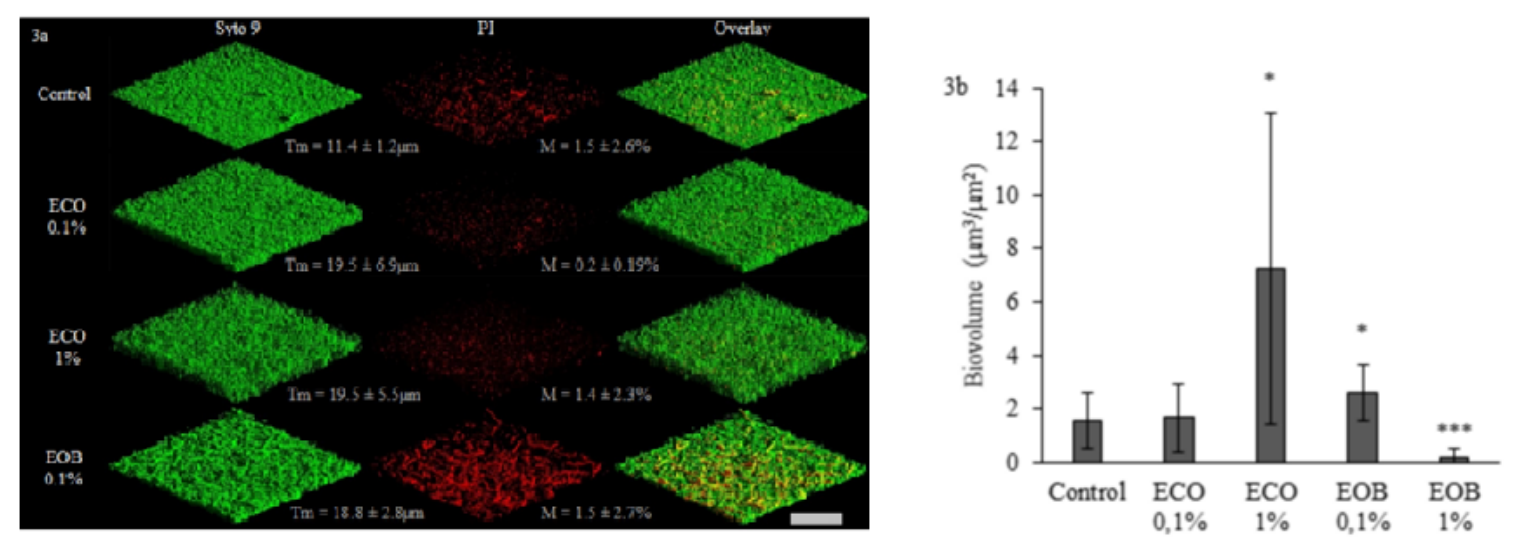

Figure 3: 3D fluorescence microscopic visualisation of PAO1 biofilms grown in different conditions (3a) and corresponding biovolumes (3b). PAO1 biofilms were performed in 3 well chambered cover glasses under $2.5 \mathrm{ml} \mathrm{h}^{-1}$ flow. LB (Control), LB with $0.1 \%$ or $1 \%$ ECO or LB with $0.1 \%$ or $1 \%$ EOB emulsified with ECO in the same amount, in relation to the EOB concentrations, were used as growth media. No biofilm was observed at $1 \%$ EOB concentration (image not shown). Total biofilm cells were detected after SYTO9 (5 $\mu \mathrm{M})$ staining and appear in green, as altered cells stained with Propidium Iodid (PI, $0.3 \mu \mathrm{M})$ appear in red. The overlay represents the superposition of SYTO9 and PI stained cells images. Scale represents $67.3 \mu \mathrm{m}$. Total biovolume and maximal thickness (Tm) were obtained from SYTO9 stained cell images treated with COMSTAT. Mortality rates (M) were obtained by calculating the ratio: total biovolume (SYTO9) / altered biovolume (PI) x 100. Error bars represent standard deviation from the mean $(\mathrm{n}=9)$ and ${ }^{*} \mathrm{P}<0.05,{ }^{* * *} \mathrm{P}<0.001$.

As $1 \%$ ECO was added to the LB medium, a high augmentation of total biovolume was observed and correlated to a constant mortality rate $\left(7 \pm 5 \mu \mathrm{m}^{3} \mu \mathrm{m}^{-2}\right.$ total biovolume for $1.4 \pm 2.3 \%$ mortality, Figure 3b). Again the maximal thickness observed was $19.5 \pm 5.5 \mu \mathrm{m}$ but as we can observe on corresponding pictures, the cells were closely organized (Figure 3a, ECO 1\%). As in early biofilm formation stages, Biosurfactants play an important role while enhancing Pseudomonas Quinolone System (PQS) solubility and therefore its activity, explaining the dose dependent augmentation of biofilm formation when using ECO [41].
Finally, when the EOB was added at $1 \%$, the biofilm was totally destabilized. The total biovolume observed for this condition was 0.15 $\pm 0.27 \mu \mathrm{m}^{3} \mu \mathrm{m}^{-2}$ and mortality reached $0.25 \%$. According to these results, the blend's anti-biofilm activity seems to depend on a bactericidal activity but, in a recent publication, Kim et al. also proved the efficiency of cinnamaldehyde to affect the Quinolone Signal, pyocianin production and swarming motility of $P$ aeruginosa [15]. Another work showed the efficiency of a $1 \mathrm{mg} \mathrm{ml}^{-1}$ peppermint extract on $P$. aeruginosa bacterial adhesion and provided a $38 \%$ inhibition on preformed biofilms [2]. 


\section{Conclusion}

Due to the three methods, the effectiveness of a blend of three essential oils against a multidrug-resistant pathogen, PA01 has been proved. This work first highlighted the increased effectiveness of a blend, in comparison to pure essential oil, on planktonic cells and on biofilm formation. As expected, each essential oil contributes to global activity by targeting different mechanisms, which enlarge the spectrum of activity. CLSM enabled us to observe filamentous consortia, revealing high stress within $\mathrm{PAO} 1$ biofilms treated with $0.1 \%$ EOB. Total biofilm eradication was finally obtained when the concentration reached $1 \%$ under a constant flow. The different active concentrations obtained in each conditions highlighted the importance of varying the methods in order to obtain representative results.

These properties could be used in order to work out a preventive surface treatment using molecular grafting, or a sanitizer active on preformed biofilm. Additionally, further experiments have to be carried out in order to understand the effect of the blend at a genetic scale, to have a better understanding of the mechanism. This could lead to a combination of molecules with known antibiotics in order to obtain new treatments against multi-drug-resistant bacteria like PAO1.

\section{Acknowledgements}

This work was supported by the Brittany Regional Council (Région Bretagne). We thank CBB Capbioteck for their technical expertise and advice.

\section{References}

1. Giaouris E, Heir E, Hébraud M, Chorianopoulos N, Langsrud S, et al. (2014) Attachment and biofilm formation by foodborne bacteria in meat processing environments: Causes, implications, role of bacterial interactions and control by alternative novel methods. Meat Sci 97: 298-309.

2. Sandasi M, Leonard CM, Van Vuuren SF, Viljoen AM (2011) Peppermint (Mentha piperita) inhibits microbial biofilms in vitro. South African J Bot 77: 80-85.

3. Valeriano C, de Oliveira TLC, de Carvalho SM, Cardoso MDG, Alves E, et al. (2012) The sanitizing action of essential oil-based solutions against Salmonella enterica serotype Enteritidis S64 biofilm formation on AISI 304 stainless steel. Food Control 25: 673-677.

4. Filloux A, Vallet I (2003) Biofilm: set-up and organization of a bacterial community. Med Sci (Paris) 19: 77-83.

5. Nikaido H (2009) Multidrug resistance in bacteria. Annu Rev Biochem 78:119-146.

6. Donlan RM (2009) Preventing biofilms of clinically relevant organisms using bacteriophage. Trends Microbiol 17: 66-72.

7. Chai Z, Wang J, Tao S, Mou H (2014) Application of bacteriophage-borne enzyme combined with chlorine dioxide on controlling bacterial biofilm. LWT-Food Sci Technol 59: 1159-1165.

8. Rodrigues S, Paillard C, Dufour A, Bazire A (2014) Antibiofilm Activity of the Marine Bacterium Pseudoalteromonas sp. 3J6 Against Vibrio tapetis, the Causative Agent of Brown Ring Disease. Probiotics Antimicrob Proteins 7: 45-51.

9. Bajpai VK, Baek KH, Kang SC (2012) Control of Salmonella in foods by using essential oils: A review. Food Res Int 45:722-734.

10. Niu C, Gilbert ES (2004) Colorimetric method for identifying plant essential oil components that affect biofilm formation and structure. Appl Environ Microbiol 70: 6951-6956.

11. van Vuuren SF, Suliman S, Viljoen AM (2009) The antimicrobial activity of four commercial essential oils in combination with conventional antimicrobials. Lett Appl Microbiol 48: 440-446.
12. Nikolic M, Jovanovic KK, Markovic T, Markovic D, Gligorijevic N, et al. (2014) Chemical composition, antimicrobial, and cytotoxic properties of five Lamiaceae essential oils. Ind Crops Prod 61: 225-232.

13. Mihajilov-Krstev T, Radnovic D, Kitic D, Stojanovic-Radic Z, Zlatkovic B (2010) Antimicrobial activity of Satureja hortensis L. essential oil against pathogenic microbial strains. Arch Biol Sci 62: 159-166.

14. Faleiro ML (2011) The mode of antibacterial action of essential oils. In: A Mendez-Vilas (ed) Sci against Microb Pathog Commun Curr Res Technol Adv. Formatex Research Center, Badajoz, pp: 1143-1156.

15. Kim YG, Lee JH, Kim SI, Baek KH, Lee J (2015) Cinnamon bark oil and its components inhibit biofilm formation and toxin production. Int J Food Microbiol 195: 30-39.

16. De Oliveira MMM, Brugnera DF, Do Nascimento JA, Piccoli RH (2012) Control of planktonic and sessile bacterial cells by essential oils. Food Bioprod Process 90: 809-818.

17. Ballester-Costa C, Sendra E, Fernández-López J, Pérez-Álvarez JA, ViudaMartos M (2013) Chemical composition and in vitro antibacterial properties of essential oils of four Thymus species from organic growth. Ind Crops Prod 50: 304-311.

18. Pamp SJ, Sternberg C, Tolker-Nielsen T (2009) Insight into the microbial multicellular lifestyle via flow-cell technology and confocal microscopy. Cytometry A 75: 90-103.

19. Tolker-Nielsen T, Sternberg C (2011) Growing and Analyzing Biofilms in Flow Chambers. Curr Protoc Microbiol. pp 1B.2.1-1B.2.17.

20. Royden CS, Connors EM (2010) The detection of moving objects by moving observers. Vision Res 50: 1014-1024.

21. Yang SA, Jeon SK, Lee EJ, Shim CH, Lee IS (2010) Comparative study of the chemical composition and antioxidant activity of six essential oils and their components. Nat Prod Res 24: 140-151.

22. Kiralan M, Bayrak A, Abdulaziz OF, Özbucak T (2012) Essential oil composition and antiradical activity of the oil of Iraq plants. Nat Prod Res 26: $132-139$.

23. Casella S, Leonardi M, Melai B, Fratini F, Pistelli L (2013) The role of diallyl sulfides and dipropyl sulfides in the in vitro antimicrobial activity of the essential oil of garlic, Allium sativum $L$, and leek, Allium porrum $L$. Phytother Res 27: 380-383.

24. Giordani R, Regli P, Kaloustian J, Portugal H (2006) Potentiation of antifungal activity of amphotericin B by essential oil from Cinnamomum cassia. Phytother Res 20: 58-61.

25. Andrade BFMT, Barbosa LN, da Silva PI, Fernandes JA (2014) Antimicrobial activity of essential oils. J Essent Oil Res 26: 34-40.

26. Burt S (2004) Essential oils: their antibacterial properties and potential applications in foods-a review. Int J Food Microbiol 94: 223-253.

27. Sangwan NS, Farooqi AHA, Shabih F, Sangwan RS (2001) Regulation of essential oil production in plants. Plant Growth Regul 34: 3-21.

28. Tsai ML, Wu CT, Lin TF, Lin WC, Huang YC, et al. (2013) Chemical Composition and Biological Properties of Essential Oils of Two Mint Species. Trop J Pharm Res 12: 577-582.

29. Trombetta D, Castelli F, Sarpietro MG, Venuti V, Cristani M, et al. (2005) Mechanisms of antibacterial action of three monoterpenes. Antimicrob Agents Chemother 49: 2474-2478.

30. Ankri S, Mirelman D (1999) Antimicrobial properties of allicin from garlic. Microbes Infect 1: 125-129.

31. Perez-Giraldo C, Cruz-Villalon G, Sanchez-Silos R, Martinez-Rubio R, Blanco MT, et al. (2003) In vitro activity of allicin against Staphylococcus epidermidis and influence of subinhibitory concentrations on biofilm formation. J Appl Microbiol 95: 709-711.

32. Ross ZM, O'Gara EA, Hill DJ, Sleightholme HV, Maslin DJ (2001) Antimicrobial properties of garlic oil against human enteric bacteria: evaluation of methodologies and comparisons with garlic oil sulfides and garlic powder. Appl Environ Microbiol 67: 475-480.

33. Chen GW, Chung JG, Ho HC, Lin JG (1999) Effects of the garlic compounds diallyl sulphide and diallyl disulphide on arylamine $\mathrm{N}$ acetyltransferase activity in Klebsiella pneumoniae. J Appl Toxicol 19: 75-81. 
Citation: Lang M, Rodrigues S, Boulho R, Duteil E, Bazire A, et al. (2016) An Essential Oil Blend Prevents Pseudomonas aeruginosa PA01 from Forming Biofilms. J Bacteriol Parasitol 7: 268. doi:10.4172/2155-9597.1000268

Page 8 of 8

34. Tsao S, Yin M (2001) In vitro activity of garlic oil and four dially sulphides against antibiotic-resistant Pseudomonas aeruginosa and Klebsiella pneumoniae. J Antimicrob Chemother 47: 665-670.

35. Prabuseenivasan S, Jayakumar M, Ignacimuthu S (2006) In vitro antibacterial activity of some plant essential oils. BMC Complement Altern Med 6: 39.

36. Ooi LS, Li Y, Kam SL, Wang H, Wong EY, et al. (2006) Antimicrobia activities of cinnamon oil and cinnamaldehyde from the Chinese medicinal herb Cinnamomum cassia Blume. Am J Chin Med 34: 511-522.

37. Domadia P, Swarup S, Bhunia A, Sivaraman J, Dasgupta D (2007) Inhibition of bacterial cell division protein FtsZ by cinnamaldehyde. Biochem Pharmacol 74: 831-840.

38. Glover RE, Smith RR, Jones MV, Jackson SK, Rowlands CC (1999) An EPR investigation of surfactant action on bacterial membranes. FEMS Microbiol Lett 177: 57-62.
39. Szczepanski S, Lipski A (2014) Essential oils show specific inhibiting effects on bacterial biofilm formation. Food Control 36: 224-229.

40. Burt SA, van der Zee R, Koets AP, de Graaff AM, van Knapen F, et al. (2007) Carvacrol induces heat shock protein 60 and inhibits synthesis of flagellin in Escherichia coli O157:H7. Appl Environ Microbiol 73: 4484-4490.

41. Van Hamme JD, Singh A, Ward OP (2006) Physiological aspects. Part 1 in a series of papers devoted to surfactants in microbiology and biotechnology. Biotechnol Adv 24: 604-620.

42. Jones TH, Vail KM, McMullen LM (2013) Filament formation by foodborne bacteria under sublethal stress. Int J Food Microbiol 165: 97-110. 